\title{
Identificación de Fases y Precipitados por MFA en Uniones de Acero Inoxidable Dúplex
}

\author{
María Eugenia Herrera López¹, Eduardo Hurtado Delgado ${ }^{1}$ David Torres Torres², Ana María Arizmendi Morquecho² \\ 1 Corporación Mexicana de Investigación en Materiales, Posgrado, Saltillo, Coahuila, México. \\ 2 Centro de Investigación en Materiales Avanzados, S.C., Unidad Monterrey, Apodaca, Nuevo León, México.
}

Recibido: 08 Jun., 2016

Aprobado: 27 Jun., 2016

E-mail: mherrera@comimsa.com (MEHL)
Resumen: La Microscopía de Fuerza Atómica (MFA), técnica de caracterización que genera imágenes topográficas de superficies a muy altas resoluciones, opera registrando los detalles de relieve superficial del material con un cantiléver que se mueve sobre la muestra, mientras un detector piezoeléctrico monitorea los cambios de altura. Ésta técnica, adquiere relevancia en el campo de la identificación de fases, partículas y precipitados a niveles de nanoescala por lo que se propone para su identificación en la zona de fusión de componentes soldados y para la identificación temprana de fallas por agrietamiento. Es una técnica que no requiere de muestras conductoras, o la especial preparación metalográfica de probetas como es el caso de la microscopia electrónica. El material de estudio es un acero inoxidable dúplex 2205, unido por arco metálico y electrodo de tungsteno (GTAW). Al material soldado se le practicó ensayo de tensión. Las probetas fueron caracterizadas mediante microscopia óptica, microscopía electrónica de barrido, microscopía de fuerza atómica y pruebas de nanoindentación. Los resultados se concentran en la identificación de las características magnéticas, topográficas y dureza específicos de cada una de las fases, partículas y regiones presentes en el metal base, zona de fusión y la zona deformada por la fractura.

Palabras clave: Microscopia de fuerza atómica; Austenita; Acero inoxidable dúplex; Ferrita; GTAW; nanointentación.

\section{Identification of Phases and Precipitates by AFM in Duplex Stainless Steel Unions}

\begin{abstract}
Atomic Force Microscopy (AFM) is a characterization technique that generates topographic images of surfaces at very high resolutions, and operates recording details of surface relief of material with a cantilever that moves on the sample, while a piezoelectric detector monitors changes in height. It acquires relevance in the field of identification phase, particles and precipitation at nanoscale level so, it is proposed for identification in the fusion zone of welded components and for the early identification of failures by cracking. It is a technique that does not require conductive samples, or special preparation of metallographic specimens such as electron microscopy. The study material is a duplex stainless steel 2205, joined by Gas Metal Arc Welding (GTAW). This material was performed tensile test. The specimens were characterized by optical microscopy, scanning electron microscopy, atomic force microscopy and nanoindentation tests. Results focus on the identification of the magnetic characteristics, and specific topography of each of the phases, regions and particles present in the base metal and weld zone as well in the crack deformed by fracture.
\end{abstract}

Key-words: Atomic force microscopy; Austenite; Duplex stainless steel; Ferrite; GTAW; nanoindentation.

\section{Introducción}

Los temas de seguridad y confiabilidad de operación de los equipos, son temas centrales en sectores estratégicos como lo son los de la industria petroquímica, campos en los que se requiere del desarrollo de técnicas y métodos más precisos y sofisticados para la evaluación de la situación presente y vida remanente de componentes [1].

Derivado de los exigentes ambientes de operación, en cuanto a resistencia mecánica y corrosividad en los que trabajan los equipos y componentes industriales dedicados a la extracción, conducción y refinación de crudo, es que desde hace tiempo se han ido introduciendo aceros inoxidables martensíticos y dúplex, los cuales presentan un 
sobresaliente desempeño en estos campos y son capaces de enfrentar entornos con altos niveles de sulfuro de hidrógeno, dióxido de carbono, cloruros y de manera general ambientes clasificados como ácidos [2-4] . Los aceros inoxidables dúplex (DSS, por sus siglas en inglés) son llamados así, debido a la presencia de las fases (a temperatura ambiente) ferrita y austenita [5-7]. No obstante, las sobresalientes propiedades de resistencia mecánica y contra la corrosión de estos materiales, al momento de ser soldados, si no se tiene cuidado con los parámetros a emplear, particularmente con aquellos asociados al calor de entrada [8-12], se produce un desbalance microestructural entre las fases ferrita y austenita causando la pérdida o deterioro de las propiedades de resistencia que tan atractivos los hacen $[5,13,14]$. Debido a su composición química, estos materiales son altamente propensos a la precipitación de fases secundarias en el rango aproximado de $600-1000^{\circ} \mathrm{C}$, las cuales incluyen las fases intermetálicas como la fase sigma $(\sigma)$, la fase Chi $\left(X_{i}\right)$, alfa prima $\left(\alpha^{\prime}\right)$, etc.; carburos del tipo $\mathrm{M}_{7} \mathrm{C}_{3}$ y $\mathrm{M}_{23} \mathrm{C}_{6}$ y nitruros del tipo $\mathrm{Cr}_{2} \mathrm{~N}$. Estas reacciones de precipitación, son dependientes del tiempo y la temperatura y la mayoría de ellas, tienden a fragilizar a las aleaciones dúplex, afectando su comportamiento y desempeño [6,15-21].

La comprensión del comportamiento microestructural de componentes o elementos industriales de aceros estructurales bajo condiciones exigentes de operación ha sido objeto de múltiples estudios [3,4,16,22,23], que dan cuenta de cómo la microscopia de fuerza atómica presenta grandes ventajas para la obtención rápida y confiable de datos, lo anterior debido a la preparación básica que requieren las superficies a analizar y por la posibilidad de emplear versiones portátiles de estos equipos directamente en el campo, permitiendo la obtención de información a nivel nanométrico de la evolución microestructural de una componente en servicio y proceder a la evaluación de su condición presente de operación y su vida remanente [22-25].

Por otra parte, si bien es cierto que se han conducido estudios que involucran la microscopia de fuerza atómica como medio de evaluación de componentes industriales como se ha venido mencionando, existe un gran campo de estudio nuevo cuando se trata de aceros inoxidables como los dúplex, materiales semimagnéticos y de su evolución y cambio microestructural cuando han sido soldados por procesos de arco [26-30].

\section{Experimentación}

Las actividades de experimentación se organizaron de la siguiente manera: Recepción del material, posteriormente se realizó la preparación de las placas para unirlo mediante el proceso GTAW. Una vez unido el material, se maquinaron las probetas de tensión de acuerdo a ASME Sección IX. Las muestras correspondientes fueron ensayadas para la prueba de tensión para la evaluación de sus propiedades mecánicas, tal y como puede observarse a continuación en la Figura 1.

Posteriormente fueron preparadas las probetas para caracterizar por microscopía óptica (MO) equipo marca Olympus y microscopía electrónica de barrido (MEB) equipo de la marca JEOL JSM-6490L Scanning Electron Microscope con analizador INCA X-SIGHT OXFORD INSTRUMENTS modelo 7573, microscopia de fuerza atómica (MFA) con un equipo HybriD ${ }^{\mathrm{TM}}$ y nanoindentador TI 950 Triboindenter-Hysitron. Finalmente se registraron los resultados para la posterior integración del apartado de conclusiones.

La composición química del metal base empleando es un DSS 2205 misma que se describe como sigue en la Tabla 1. Las dimensiones del cupón del material base fueron de $25 \mathrm{~cm} \times 21 \mathrm{~cm} \times 10 \mathrm{~mm}$. El número UNS del acero inoxidable dúplex 2205 corresponde a un S32205.

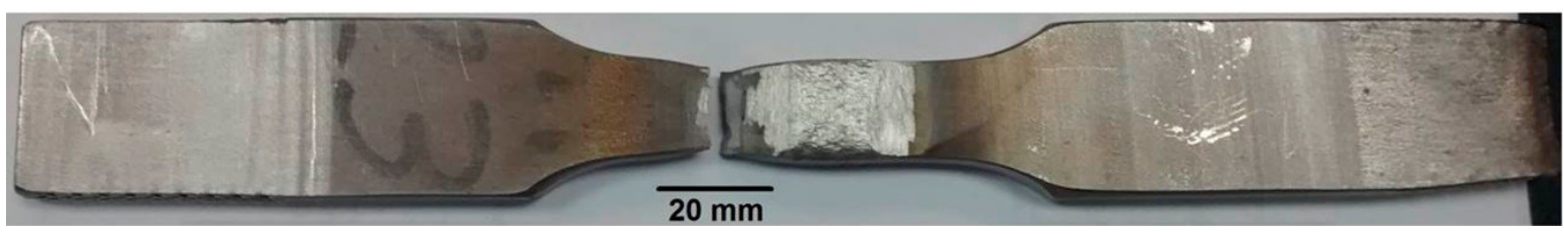

Figura 1. Ejemplar de probeta de tensión de donde se extrajeron las muestras para caracterización.

Tabla 1. Composición química del metal base DSS 2205\% en peso.

\begin{tabular}{ccccccccccccc}
\hline Elemento & $\boldsymbol{C}$ & $\mathbf{S i}$ & $\mathbf{M n}$ & $\boldsymbol{P}$ & $\boldsymbol{S}$ & $\boldsymbol{C r}$ & $\mathbf{N i}$ & $\mathbf{M o}$ & $\mathbf{N b}$ & $\mathbf{C u}$ & $\mathbf{C o}$ & $\boldsymbol{N}$ \\
\% en peso & 0,016 & 0,47 & 1,42 & 0,026 & 0,001 & 22,41 & 5,73 & 3,13 & 0,007 & 0,28 & 0,16 & 0,179 \\
\hline
\end{tabular}


El metal de aporte empleado es un A5.9 (Especificación SFA) y ER 2209 (No. AWS) en calibres de 3/32 y 1/8 de pulgada. La composición química se detalla en la Tabla 2, mismos que corresponden a los reportados por el fabricante.

En cuanto a la soldadura por GTAW, se prepararon las láminas de acero de $10 \mathrm{~mm}$ de espesor para ser soldadas en una junta de ranura en $V$ sencilla, de acuerdo al detalle señalado a continuación en la Figura 2 y utilizando como gas de protección argón al 99.98\%. El electrodo empleado fue un EWRH-2 de 3/32 de pulgadas de diámetro.

Los parámetros utilizados para la unión de los aceros inoxidables dúplex del presente estudio se indican en la Tabla 3.

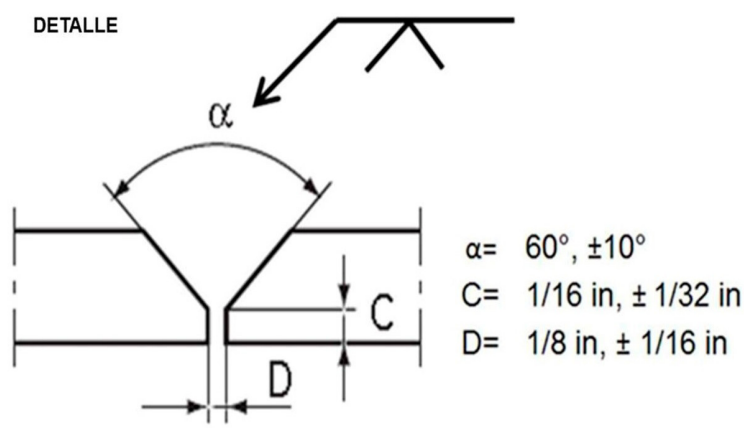

Figura 2. Preparación de la junta para las placas de acero inoxidable dúplex 2205 empleadas en el estudio.

Tabla 2. Composición química del metal de aporte $2209 \%$ en peso.

\begin{tabular}{ccccccccccc}
\hline Elemento & $\mathbf{C}$ & $\mathbf{S i}$ & $\mathbf{M n}$ & $\boldsymbol{P}$ & $\boldsymbol{S}$ & $\mathbf{C r}$ & $\mathbf{N i}$ & $\mathbf{M o}$ & $\boldsymbol{T i}$ & $\mathbf{C u}$ \\
\% en peso & 0,01 & 0,4 & 1,4 & 0,01 & 0,001 & 22,7 & 8,5 & 3 & - & 0,06 \\
\hline
\end{tabular}

Tabla 3. Parámetros de soldadura.

\begin{tabular}{|c|c|c|c|c|c|c|c|}
\hline \multirow{2}{*}{ No. Pase } & \multirow{2}{*}{ Proceso } & \multicolumn{2}{|c|}{ Metal de aporte } & \multirow{2}{*}{$\begin{array}{c}\text { Corriente y tipo } \\
\text { de polaridad }\end{array}$} & \multirow{2}{*}{ Amperaje } & \multirow{2}{*}{ Voltaje } & \multirow{2}{*}{ Velocidad } \\
\hline & & Clasificación & Diámetro & & & & \\
\hline 1 & GTAW & ER2209 & 3/32 pulg & CDEN & 165 & 17 & $3 \mathrm{pulg} / \mathrm{min}$ \\
\hline 2 & GTAW & ER2209 & 3/32 pulg & CDEN & 165 & 17 & $3 \mathrm{pulg} / \mathrm{min}$ \\
\hline $3-n$ & GTAW & ER2209 & 1/8 pulg & CDEN & 190 & 18 & $3 \mathrm{pulg} / \mathrm{min}$ \\
\hline
\end{tabular}

En cuanto a las técnicas de caracterización, el espécimen de acero inoxidable dúplex fue desbastado, pulido y atacado con reactivo Beraha lo anterior con la finalidad de permitir el revelado de las microestructuras presentes, así como el aspecto físico del material después de haber sido soldado mediante el proceso GTAW y después del ensayo de tensión. La primera técnica de caracterización se llevó a cabo con la ayuda de un microscopio óptico marca OLYMPUS, modelo PMG-3. Se analizaron las muestras a diversas magnificaciones (50X, 200X y 500X). La segunda técnica de caracterización fue la microscopia electrónica de barrido (MEB) JEOL JSM-6490L Scaning Electron Microscope con un analizador INCA X-SIGHT OXFORD INSTRUMENTS modelo 7573, microscopia de fuerza atómica con un equipo $\mathrm{HybriD}^{\mathrm{TM}}$ y posteriormente se procedió a hacer las medidas de nanoindentación, así como las respectivas imágenes de topografía con un equipo TI 950 Triboindenter - Hysitron. Se emplearon analizadores de imágenes como el Gwyddion y el WSXM 5.0 Ref. [30].

\section{Resultados y Discusiones}

Es de interés de este trabajo de investigación, la caracterización de la unión soldada: zona de fusión (soldadura), zona afectada por el calor (ZAC) y metal base (MB) así como la región de fractura. A continuación en la Figura 3, es posible identificar con claridad las tres regiones de la ZF en la probeta. 
En la Figura 4, se puede apreciar la deformación plástica que experimentó el DSS, en el metal base como resultado de la prueba de tensión que se le practicó.

En la Figura 3 y Figura 4 previamente mostradas, fue posible identificar la microestructura bifásica característica de estos materiales (ferrita-austenita). Se procedió a la cuantificación de fases con la ayuda del software IMAGE PRO y se detallan los resultados a continuación.

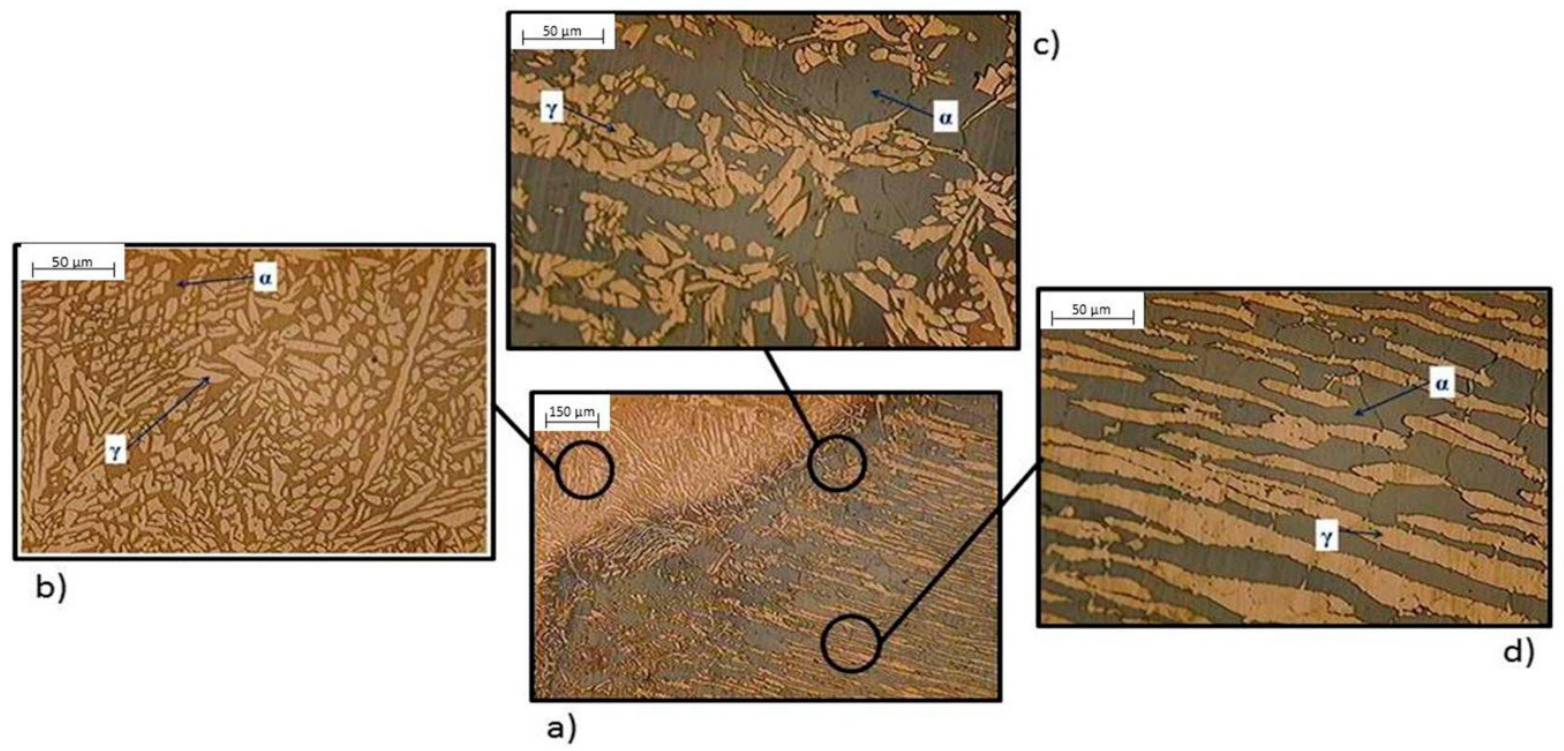

Figura 3. Microscopia óptica. Soldadura de acero inoxidable 2205. Ataque con reactivo Beraha. (a) Tres regiones a 50X, (b) Zona de fusión 500X, (c) ZAC 500X, (d) MB 500X.

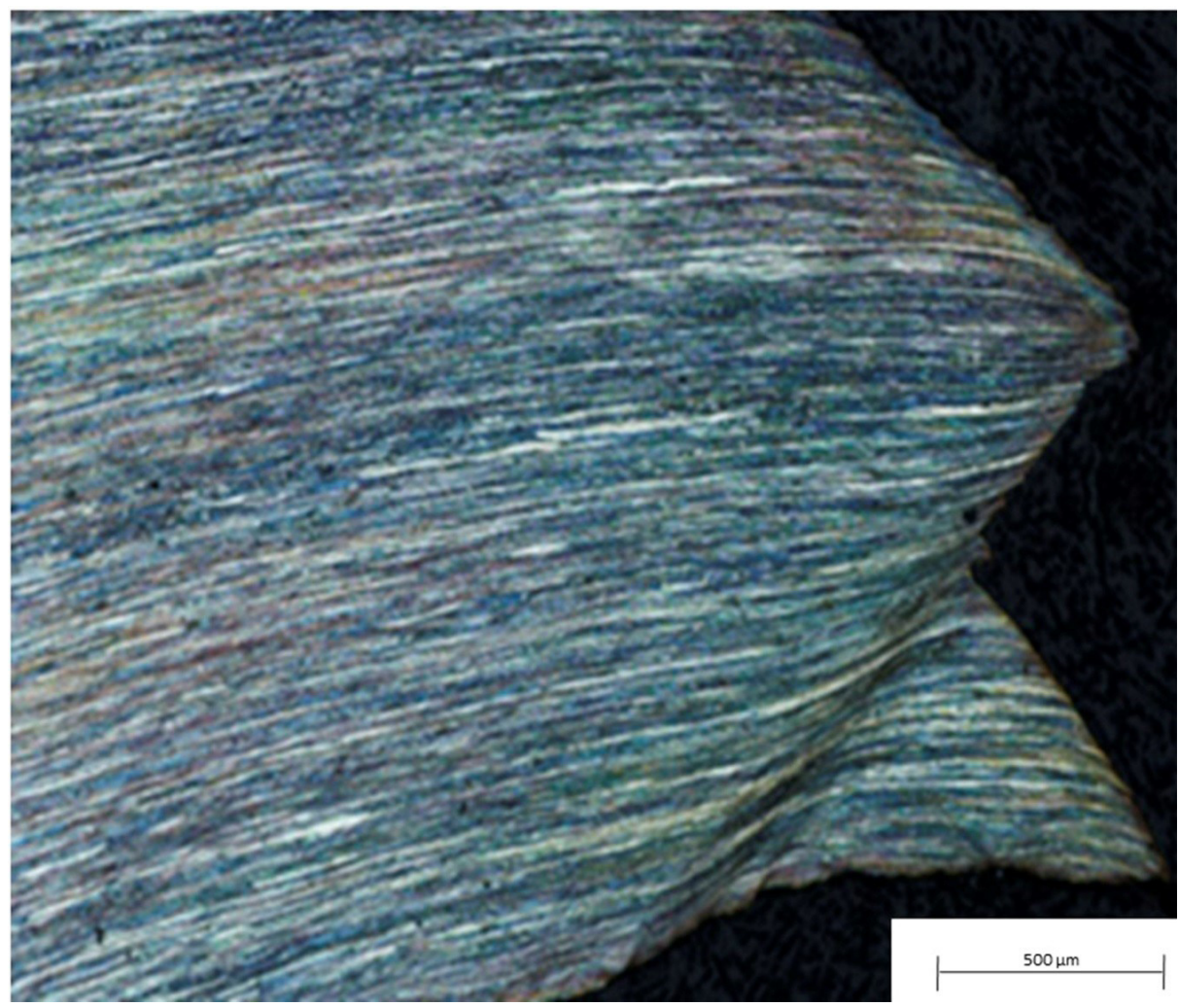

Figura 4. Microscopia óptica en zona de fractura. Ataque con reactivo Beraha. 
En el metal base se mantiene el balance microestructural de estos materiales, tal y como se observa en los resultados mostrados en la Figura 5a, en niveles de 51, 2\% ferrita y 48, 8\% austenita, ello es indicativo de que efectivamente es posible encontrar las propiedades mecánicas típicas de estos materiales encontrando también esta misma condición en la Figura 5b ZF (49, 9\% ferrita y 50, 1\% austenita).

Por otra parte, en cuanto a la ZAC, se identifica un predominio ferrítico (84, 6\%) contra una presencia austenítica significativamente menor $(15,4 \%)$, lo anterior debido a que el transcurso de la solidificación en los DSS empieza $100 \%$ como ferrítico, y ello permite la formación eventual de la austenita durante el proceso de enfriamiento (Ver Figura 6).

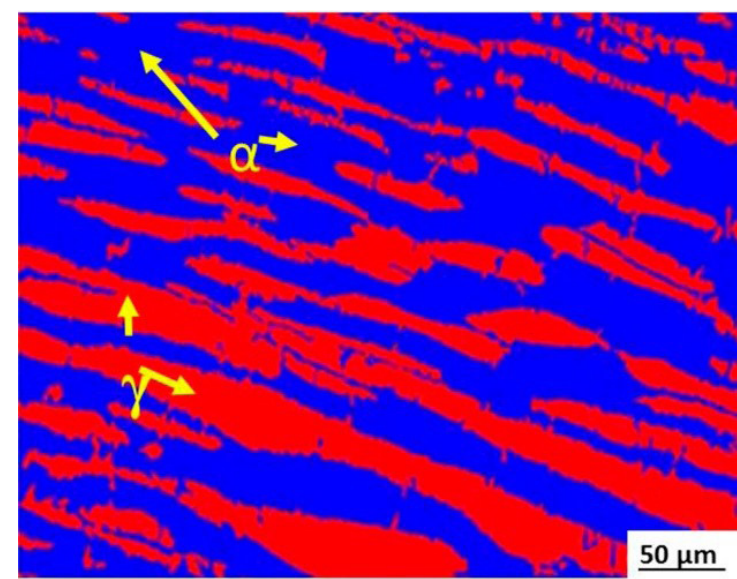

a)

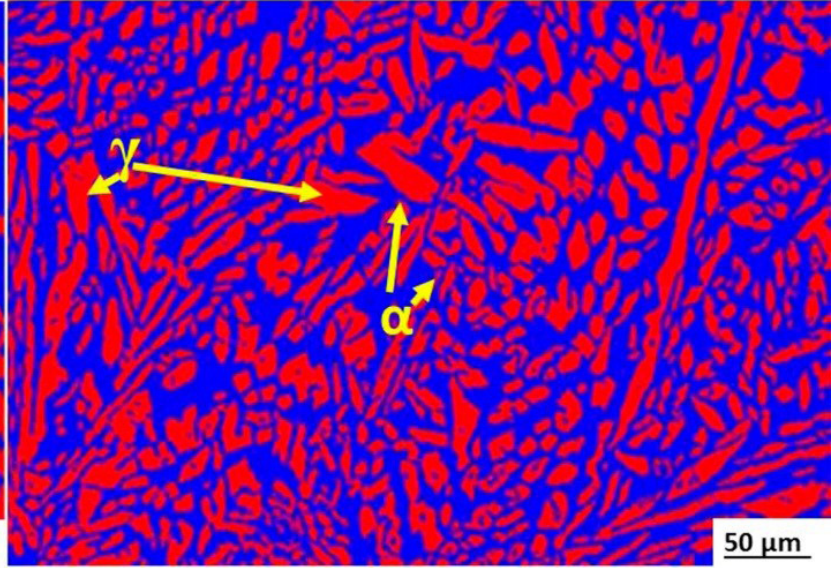

b)

Figura 5. Cuantificación de fases. (a) metal base. Tamaño de grano de ferrita 6, 8 y tamaño de grano de austenita 7, 3. Fracciones $51,2 \%$ ferrita y $48,8 \%$ austenita, (b) soldadura. Tamaño de grano de ferrita 8,3 y tamaño de grano de austenita 8,4. Fracciones 49, 9\% ferrita y 50, 1\% austenita, Método estándar ASTM E1382-97 [31].

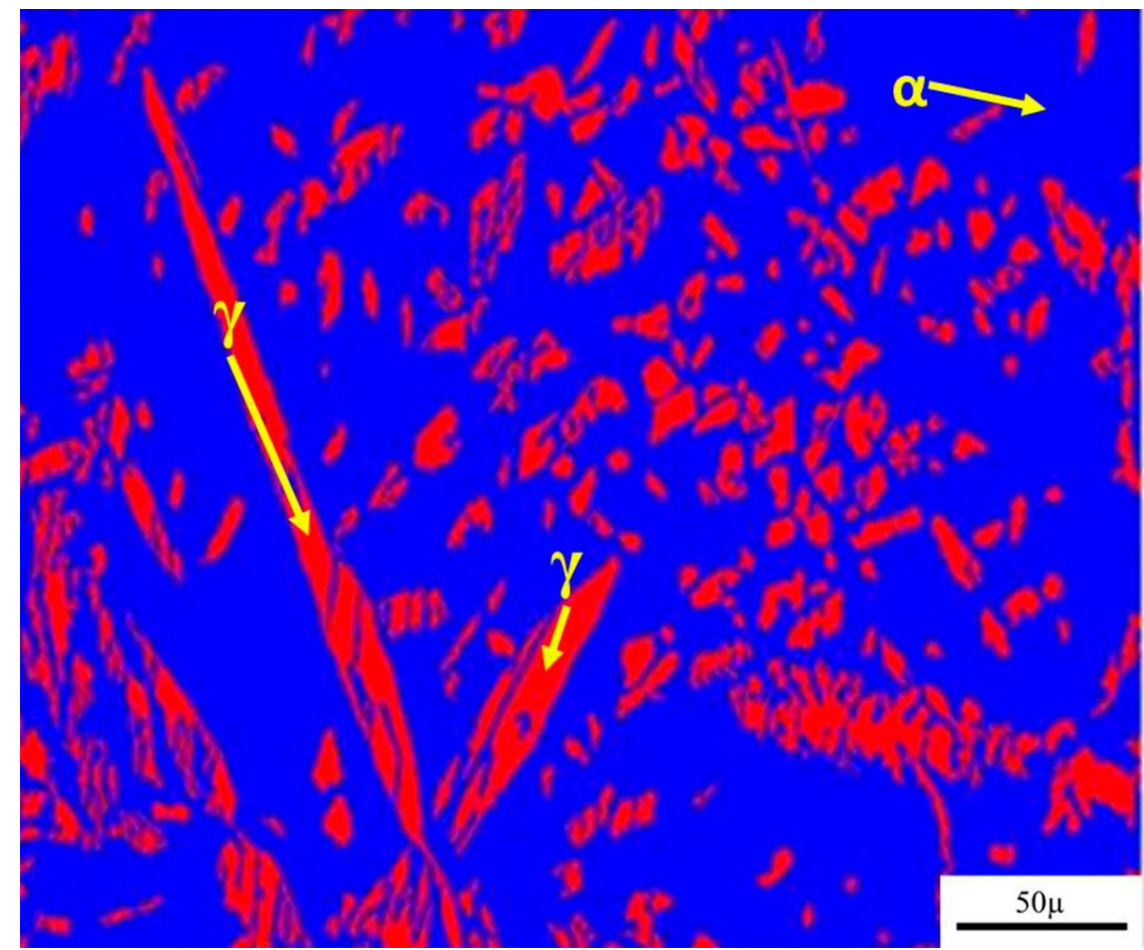

Figura 6. Cuantificación de fases en ZAC. Tamaño de grano de ferrita 5, 8. Tamaño de grano austenita $10,1$. Fracciones 84, 6\% ferrita y 15, 4\% austenita. Método estándar ASTM E1382-97 [31]. 
Los resultados obtenidos en cuanto al tamaño de grano corresponden a los proporcionados por el analizador de imágenes, empleando el Método Automático para Dos Fases. El tamaño de grano reportado por el software y de acuerdo al estándar ASTM E1382-97 [31], es adimensional, sin embargo con el objetivo de clarificar las dimensiones obtenidas en cada región en $\mu \mathrm{m}$ y de acuerdo a las mediciones realizadas se tiene:

MB medidas promedio de grano austenítico: $202,2 \mu \mathrm{m} \times 3,6 \mu \mathrm{m}$

MB medidas promedio de grano ferrítico: $84,8 \mu \mathrm{m} \times 4,0 \mu \mathrm{m}$

ZAC medidas promedio de grano austenítico: $27,1 \mu \mathrm{m} \times 3,2 \mu \mathrm{m}$

ZAC medidas promedio de grano ferrítico: $274,3 \mu \mathrm{m} \times 4,0 \mu \mathrm{m}$

ZF medidas promedio de grano austenítico: $74,0 \mu \mathrm{m} \times 4,3 \mu \mathrm{m}$

ZF medidas promedio de grano ferrítico: $69,4 \mu \mathrm{m} \times 4,1 \mu \mathrm{m}$

Como se puede observar a continuación en la Figura 7, derivado del desbalance microestructural identificado en la ZAC, se procedió a realizar una caracterización a mayor profundidad, verificando por medio del MEB si tenía lugar la identificación de morfologías diferentes a las típicas de este tipo de materiales. Como resultado de esta técnica de caracterización no se identificaron con las resoluciones empleadas estructuras distintas a la ferrita y austenita.
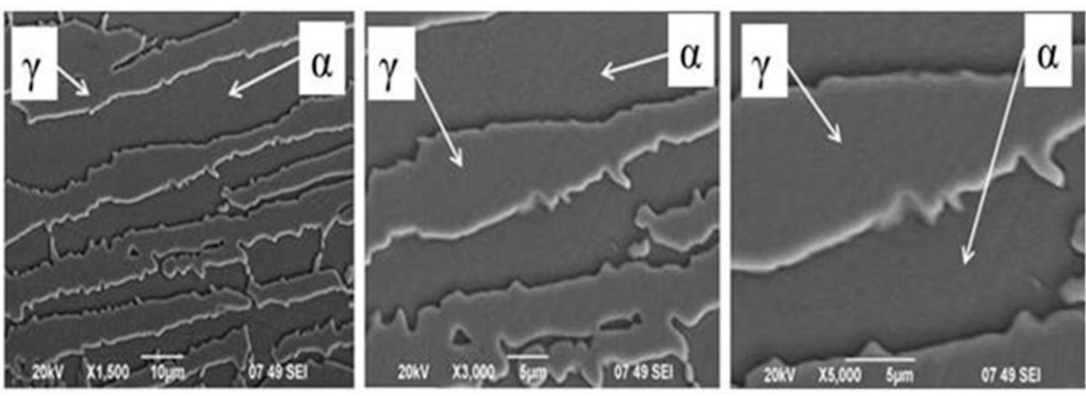

a)

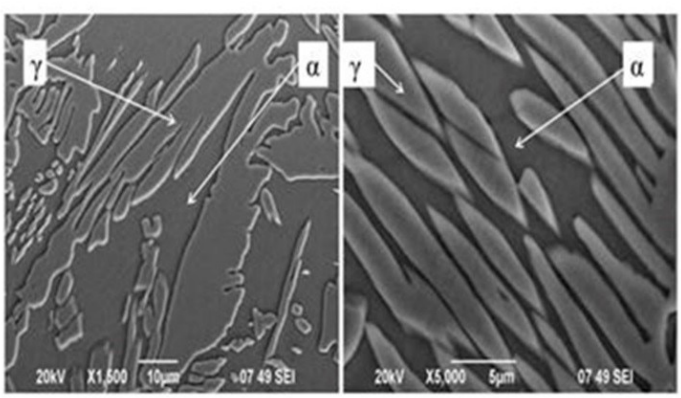

b)
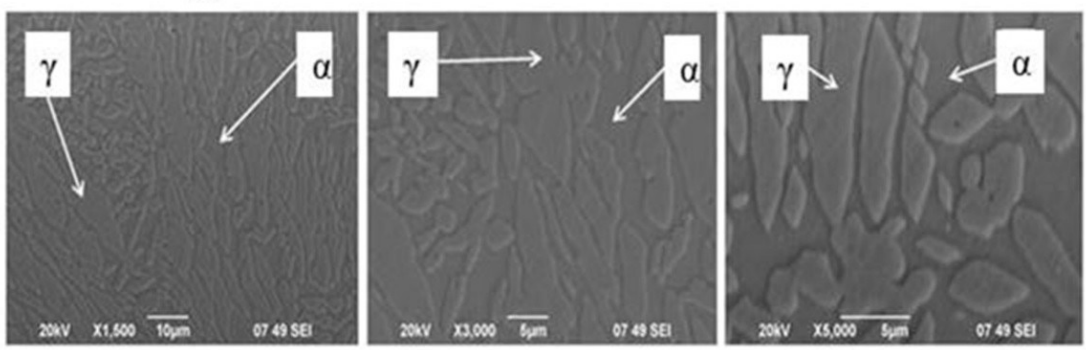

c)

Figura 7. Caracterización mediante microscopia electrónica de barrido. (a) Metal base a 1500X, 3000X y 5000X, (b) ZAC a 1500X y 5000X y, (c) Zona de fusión a 1500X, 3000X y 5000X. 
Dado que la resolución empleada a nivel de MEB no se encontró evidencia de microestructuras o partículas distintas a las típicas del material, se optó por emplear la MFA para realizar un estudio más minucioso, iniciando con una caracterización en modo magnético y de ángulo de fase en MB y en ZF del material de estudio. Como se puede observar en la Figura 8, de manera ilustrativa se muestra, cómo una probeta sin la preparación previa que requieren otras técnicas de caracterización ofrecen información relevante para el análisis de materiales. En la Figura 8a, se presenta el aspecto de la micrografía en modo topográfico, señalando una línea de inspección y de la cual se obtiene una gráfica del relieve presente, identificándose que se trata de una superficie con importantes diferencias de altura (a estas escalas). De manera complementaria la Figura 8b en modo magnético es posible distinguir la presencia de fases ferrita y austenita como resultado de las propiedades magnéticas que poseen.

Considerando la información anteriormente mostrada en la Figura 8, es posible trazar líneas de inspección en el modo de operación de ángulo de fase y escanear la imagen obtenida mediante MFA y localizar estructuras o partículas específicas en las imágenes obtenidas.

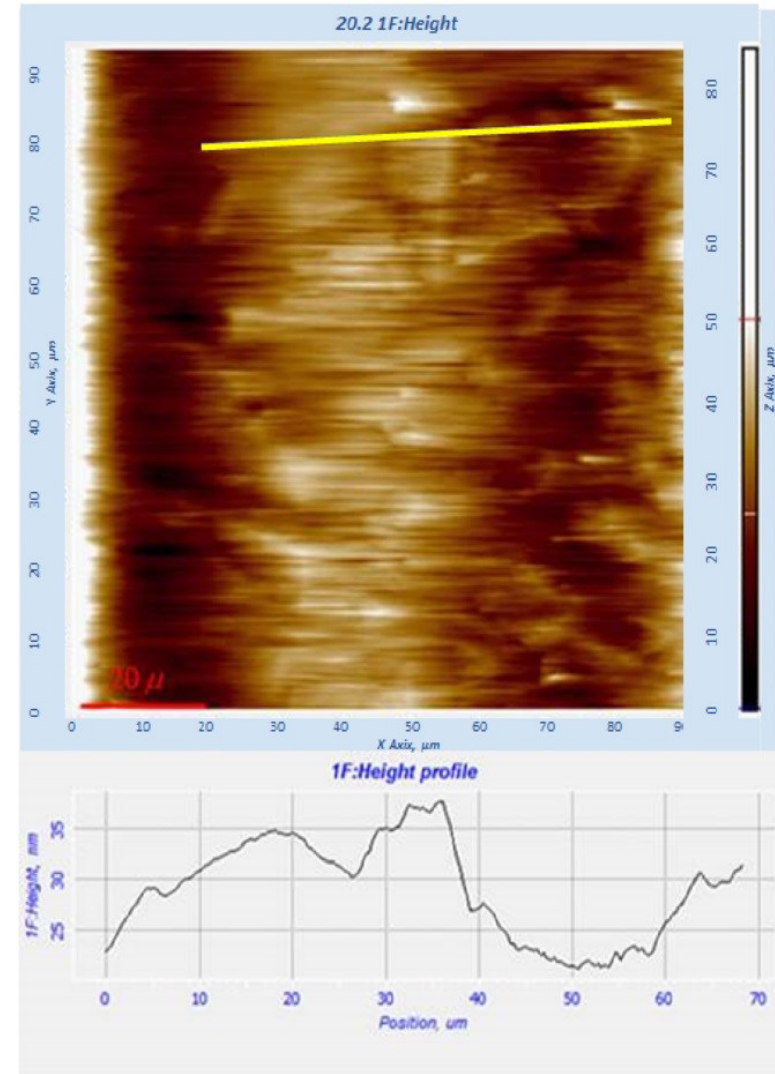

a)

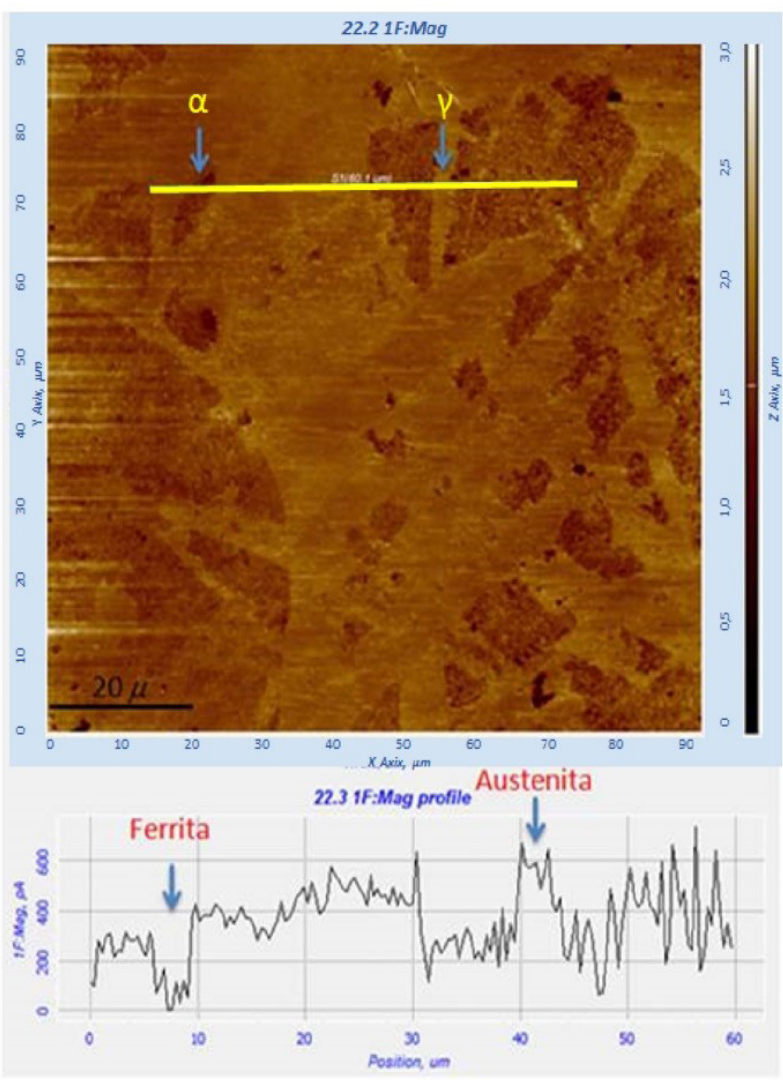

b)

Figura 8. MFA en (a) modo de operación topográfico en MB y (b) modo de operación magnético en ZF.

Al igual que en la caracterización en MFA en fuerzas magnéticas, en el modo de ángulo de fase, se identifica la respuesta del material tanto en ZF en la línea 204 como en la línea 50 de metal base (Ver Figura 9), en dónde hay respuesta puntual en puntos brillantes o zonas claras.

Aunado a los resultados anteriores, la determinación del módulo elástico efectivo en las diversas regiones del material, permite identificar comportamientos característicos de fases o partículas presentes, se trata de una prueba sumamente sensible debido a la precisión con la que se realiza la nanoindentación y el número de lecturas que se obtienen por punto (en el caso específico de este trabajo del orden de 3000 lecturas por nanoindentación). En la Figura 10, se esquematiza las regiones en las que fueron tomadas las lecturas correspondientes al metal base en zonas próximas a la ZAC. En ésta, se muestra imagen topográfica y fuerza lateral obtenida mediante MFA 


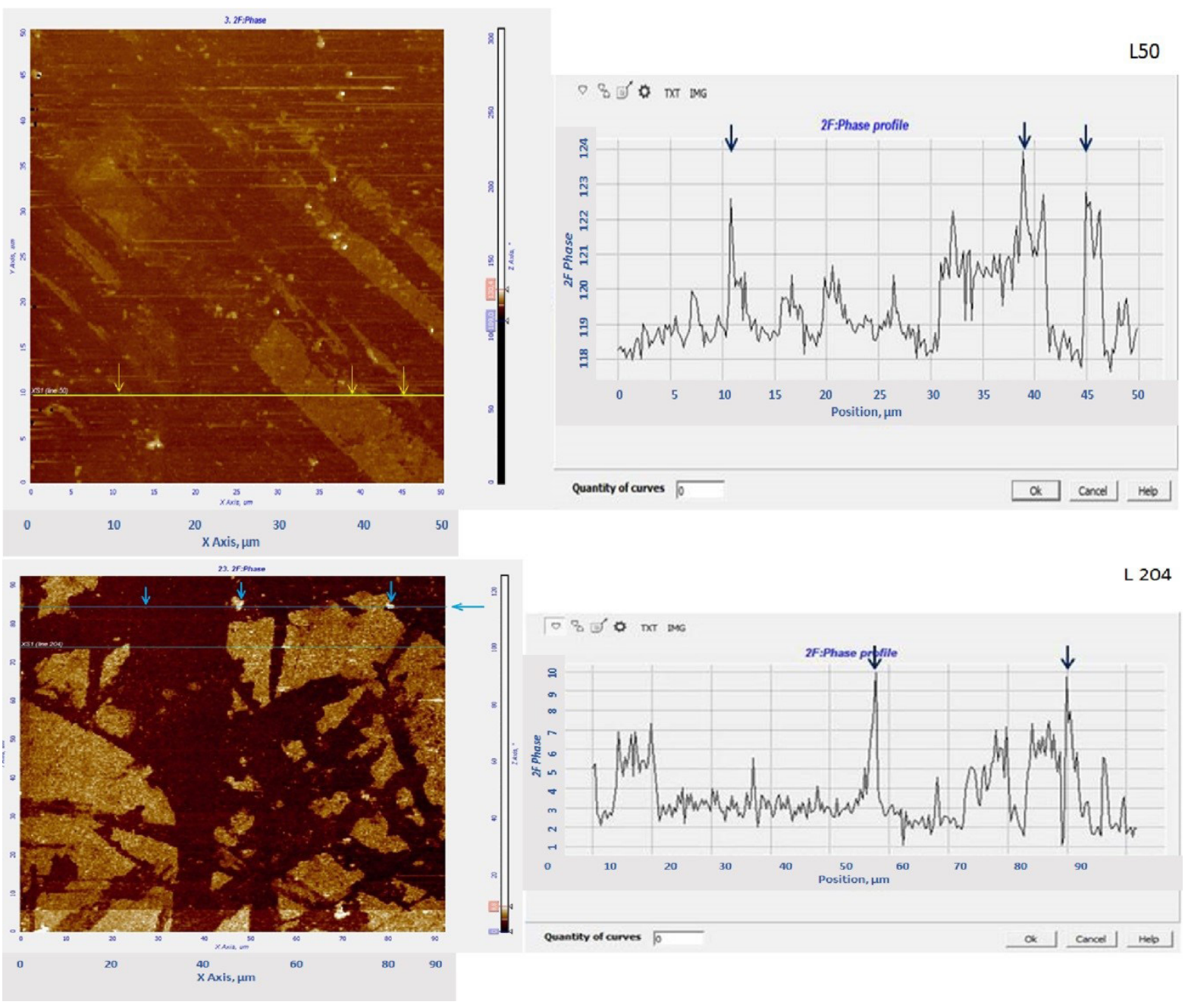

Figura 9. MFA ángulo de fase. Líneas 50 (MB) y 204 (ZF).

en dos regiones: a) en una región predominantemente austenítica como se observa en la Figura 10a y Figura 10c y en otra región ferrítica como lo muestran la Figura 10b y Figura 10d.

De la misma manera, se condujo el ensayo en la región de soldadura (Ver Figura 11) y en la zona deformada por el ensayo de tensión (Ver Figura 12).

Los resultados por región se concentran en la Figura 13. Por lo que respecta al metal base, fue posible establecer el módulo elástico efectivo de manera clara y distintiva entre las fases presentes (ferrita y austenita), como se anticipaba, la curva que representa el módulo elástico efectivo de la ferrita (Figura 13a) se encuentra desplazada hacia la derecha, indicando que, a una carga determinada, la ferrita experimenta mayor penetración que la austenita en condiciones similares. Por lo que respecta al módulo elástico efectivo obtenido en la soldadura (Ver Figura 13b), los resultados en la zona de inspección elegida (con diez nanoindentaciones, tal y como se señaló previamente en la Figura 11c y Figura 11d), es posible afirmar que se trata de una zona ferrítica (debido a sus características topográficas), aun y cuando los valores del módulo elástico efectivo correspondan a los logrados por la austenita. Lo anterior debido a que probablemente el endurecimiento de la ferrita se deba a la presencia de nitruros en la superficie inspeccionada. En la Figura 11b, se puede apreciar una topografía en la que sobresalen puntos brillantes en cúmulos de partículas que de la misma manera parecen responder al análisis en MFA en modo magnético y ángulo de fase, como ya se indicó previamente en la Figura 8 y Figura 9. 


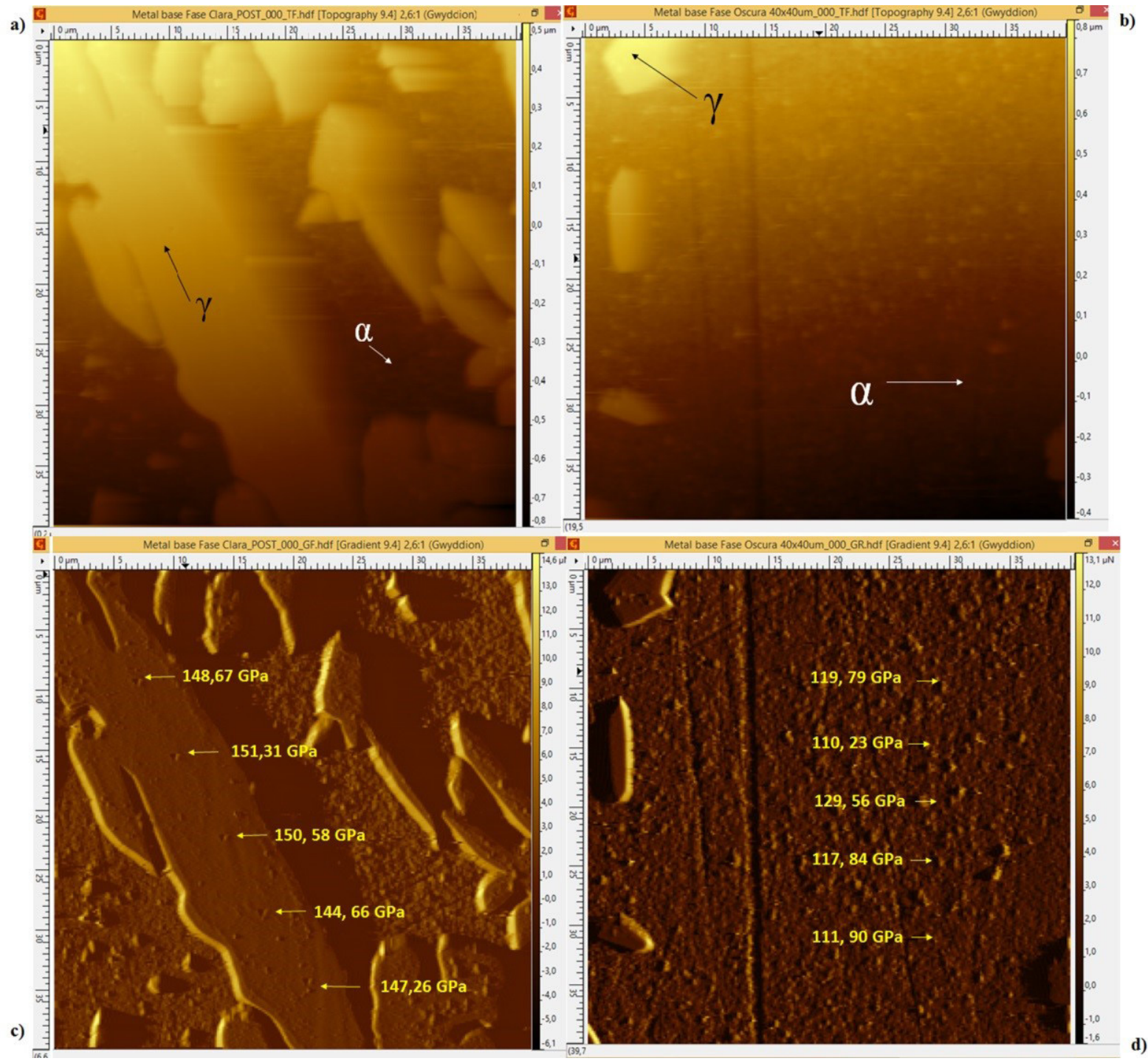

Figura 10. Caracterización del metal base mediante MFA. (a) Modo de operación topográfico en $\mu$ m en un campo predominantemente austenítico, (b) modo de operación topográfico en $\mu \mathrm{m}$ en un campo predominantemente ferrítico, (c) modo de operación de contacto (fuerza lateral en $\mu \mathrm{N}$ ), huellas y valores del módulo elástico efectivo obtenidos mediante nanoindentación en grano austenítico, (d) modo de operación de contacto (fuerza lateral en $\mu \mathrm{N}$ ), huellas y valores de módulo elástico efectivo obtenidos mediante nanoindentación en grano ferrítico.

Finalmente, en cuanto al comportamiento obtenido en la zona deformada por el ensayo de tensión y con presencia de grieta, de las 13 nanoindentaciones practicadas (Ver Figura 12b), el módulo elástico efectivo identificado en esa zona experimenta también un comportamiento similar al de la austenita, lo anterior debido a la deformación plástica que se produjo durante el ensayo de tensión. En este caso no podría decirse que el comportamiento mecánico de la zona se deba a algún fenómeno de precipitación, ya que la cuantificación de fases en esta zona se encuentra en equilibrio de fases. Asimismo los resultados en esta zona son concordantes con los obtenidos por Bhattacharjee et al. [32], Pauletti et al. [33], Shamanian et al. [34] en 2014, 2013 y 2015 respectivamente, reportan que los mayores valores de dureza en esta zona son debidos a la orientación de planos cristalinos existentes.

A manera de discusión y como producto de la información obtenida para análisis, se hace énfasis en los siguientes aspectos:

Por cuantificación de fases se tiene información de que en la soldadura existe un balance microestructural de ferrita y austenita aproximada al 50\% por cada una, sin embargo, la zona de ensayo para la realización de la 

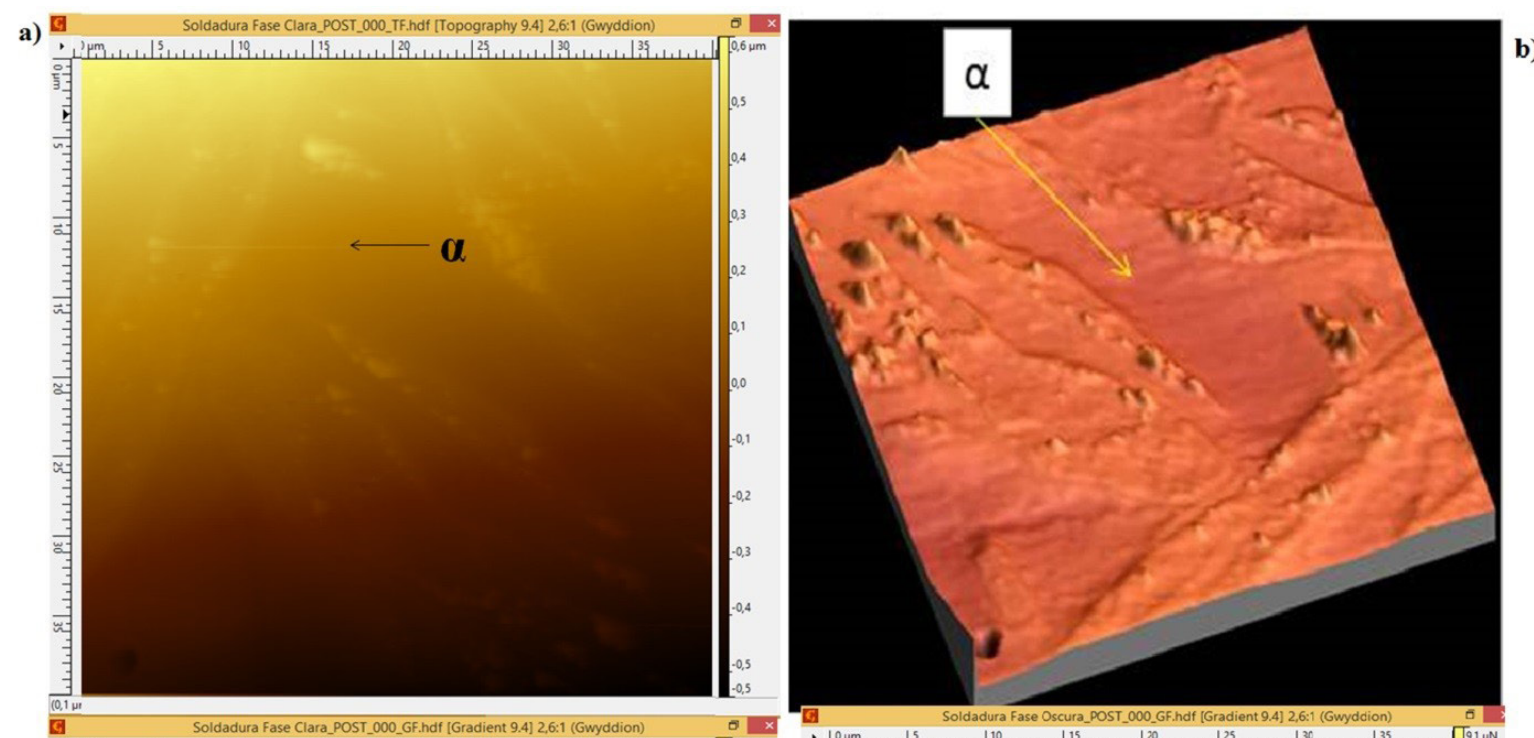

b)
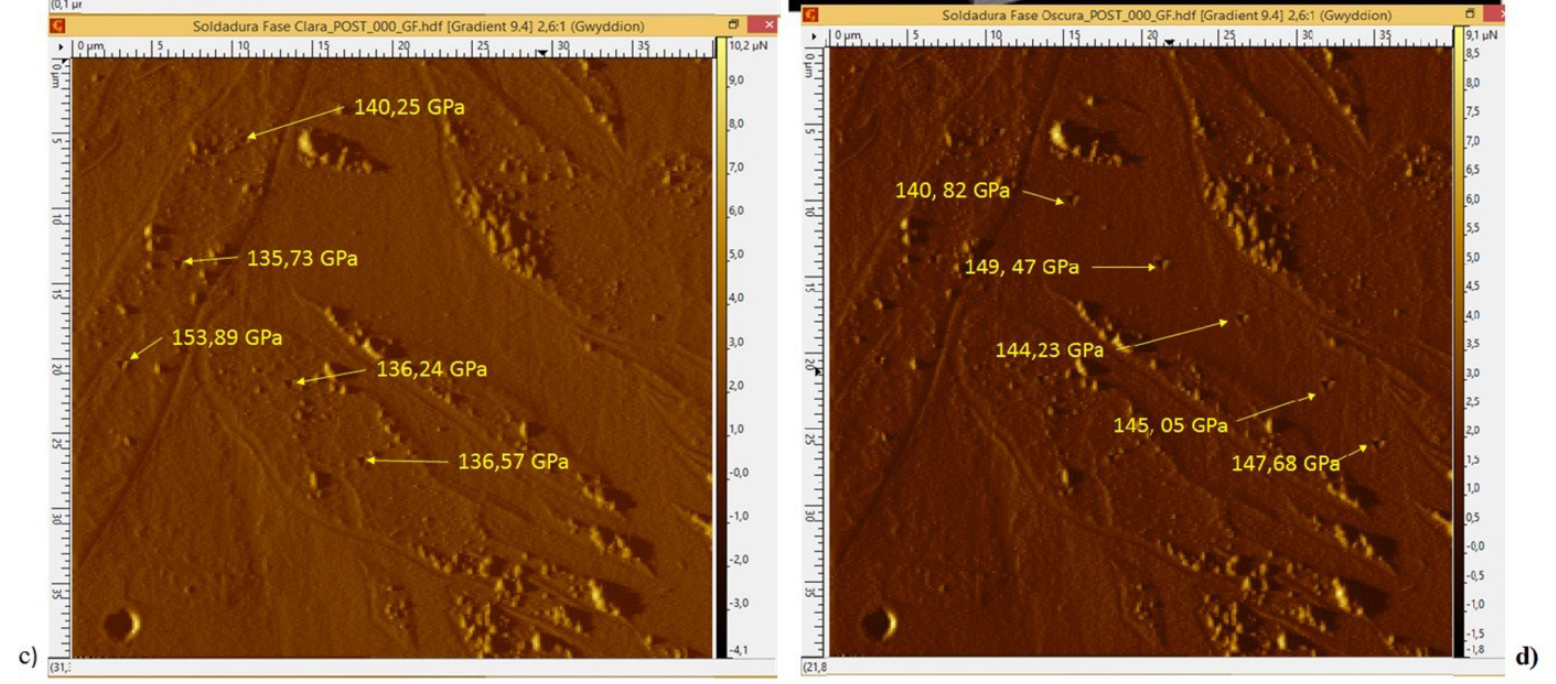

Figura 11. Soldadura caracterizada mediante MFA. (a) Modo de operación topográfico en $\mu \mathrm{m}$, (b) imagen en 3D mostrando el relieve de la superficie de la soldadura, (c) y (d) modo de operación de contacto (fuerza lateral en $\mu \mathrm{N})$, huellas y valores del módulo elástico efectivo obtenidos mediante nanoindentación en cúmulos de granos pequeños de ferrita.

nanoindentación, se identifica la presencia predominante de ferrita, lo anterior se explica teniendo como punto de partida en el diagrama $\mathrm{Fe}-\mathrm{Cr}-\mathrm{Ni}$, y dadas las condiciones prevalecientes durante el fenómeno de enfriamiento, la composición química del metal base, del metal de aporte, las temperaturas presentes, los tiempos de enfriamiento y el crecimiento son promotores de la formación de una ferrita fuera de equilibrio que trasciende el campo $\gamma+\delta$ para alcanzar temperaturas en las que tiene lugar la formación incipiente de granos austeníticos al interior de la misma ferrita.

Al tener una fase ferrítica fuera del equilibrio en la soldadura, es posible que se hayan dado condiciones para la precipitación de elementos como nitrógeno y su posterior conversión en nitruros.

Lo anterior tiene repercusiones no sólo en el empobrecimiento del metal producto de la precipitación, sino por el efecto endurecedor que tiene el cromo de compuestos como nitruros de cromo.

Los productos de este proceso termodinámico son detectados a niveles nanométrico en etapas en las que no es posible identificarlo con otras técnicas de caracterización como el MEB. 


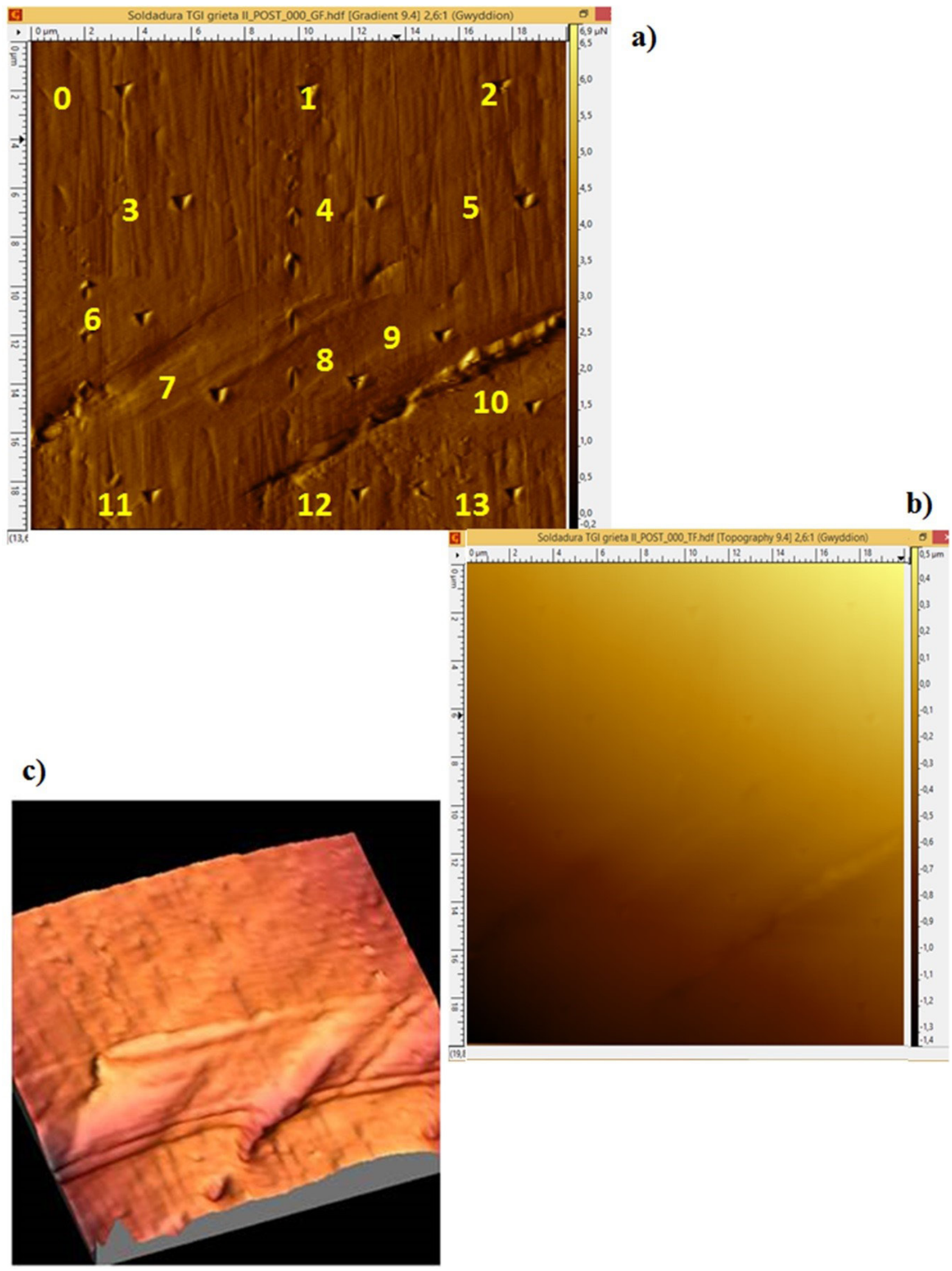

Figura 12. Zona deformada caracterizada mediante MFA: (a) Modo de operación topográfico en $\mu \mathrm{m}$, (b) modo de operación de contacto (fuerza lateral en $\mu \mathrm{N}$ ) huellas de módulo elástico efectivo obtenido mediante nanoindentación, (c) imagen 3D de la zona deformada. 
Gráficas de nanoindentación

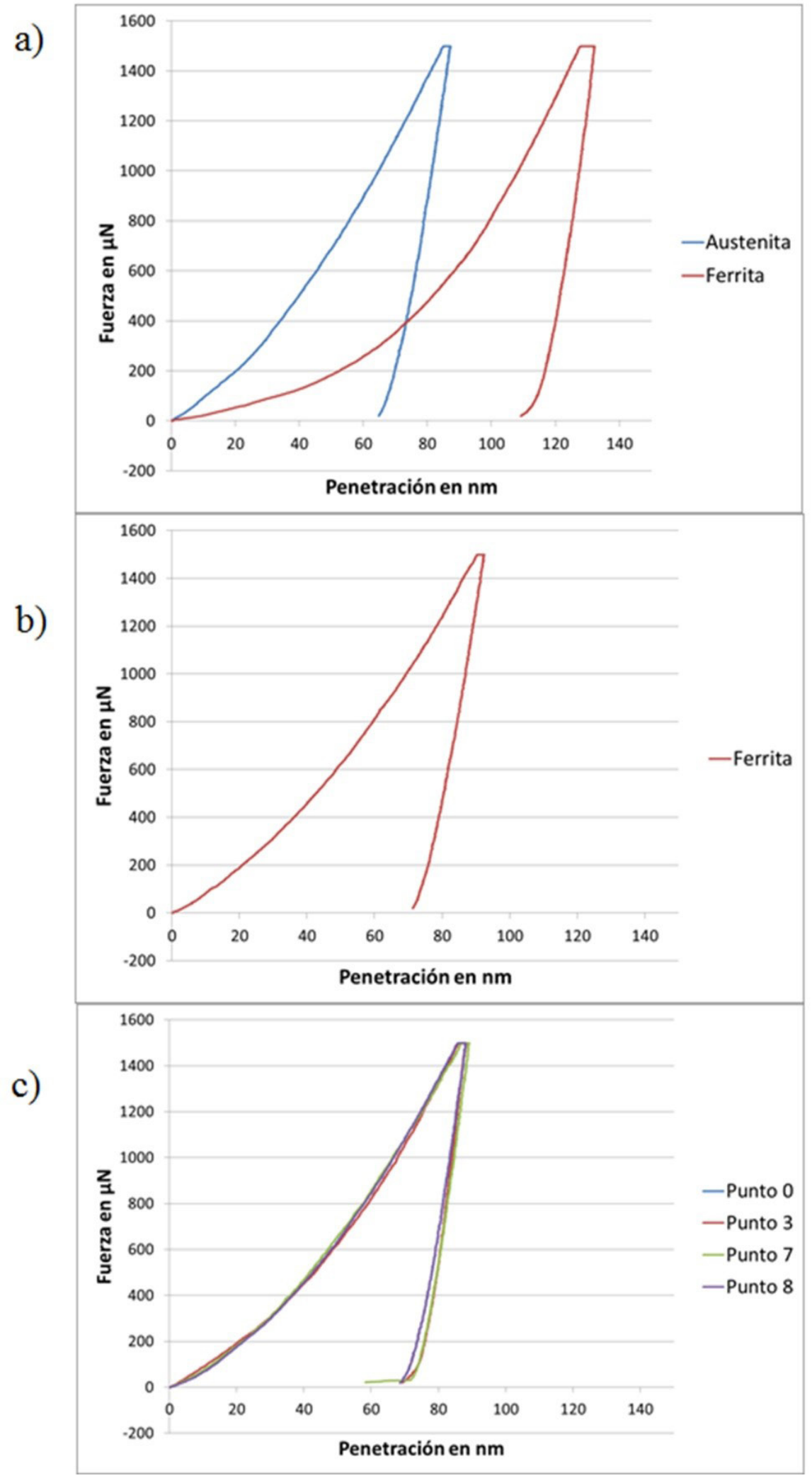

Figura 13. Comportamiento de la prueba de nanoindentación y valores del módulo elástico efectivo para: (a) metal base, (b) Zona de fusión y (c) grieta. 


\section{Conclusiones}

En el metal base:

- Los resultados obtenidos mediante las diferentes técnicas de estudio (MO, MEB, MFA, cuantificación de fases y nanoindentación), ofrecieron una clara diferenciación entre las fases ferrita y austenita tal y como se esperaba. Sin embargo, por lo que respecta a los valores dureza obtenida a escala nanométrica en esta región, la ferrita y la austenita exhiben valores menores a los comúnmente encontrados a escala macro.

En zona de fusión:

- La caracterización mediante MO y MEB, dan información que corroboran las características de la estructura bifásica ferrítico-austenítica del material en esta región, no lo es así con los datos obtenidos mediante MFA y la nanoindentación. En el caso de la MFA fue posible no sólo identificar ferrita y austenita debido a las características topográficas y magnéticas de las fases en cuestión, sino permitió la identificación de zonas con comportamientos que no corresponden a ninguna de las dos fases antes mencionadas.

- En cuanto a los datos obtenidos durante la nanoindentación, se identificó que la ferrita experimentó un endurecimiento mostrando valores en esta propiedad equiparables a los de la austenita. Por lo anterior se concluye que no debe esperarse que las curvas de nanoindentación de una misma fase en regiones distintas de una soldadura sean iguales. Es posible que el endurecimiento haya sido debido al cambio en la composición química en el material.

En la zona deformada plásticamente:

- El aumento de la dureza identificado en la ferrita es debido a la generación de textura en planos cristalinos de alta dureza.

De manera general.

- La técnica de MFA permite la obtención de imágenes y datos útiles a partir de especímenes preparados únicamente con una limpieza básica, sin los costos y tiempos de preparación metalográfica que otras técnicas requieren.

- Es posible emplear las técnicas de MFA y nanoindentación como un recurso que confiere confiablidad en la caracterización de materiales empleados en aplicaciones industriales, con la finalidad de detectar elementos que comprometen su integridad mecánica. Si bien es cierto que no existe una técnica de caracterización que ofrezca todas las ventajas y posibilidades de operación, funcionalidad, resolución, portabilidad, información, etc, éstas técnicas se constituyen como una alternativa viable para la evaluación de componentes industriales sin los tiempos y requisitos que demandan otras técnicas y con la posibilidad de detección temprana de condiciones y a nivel nanométrico de elementos perjudiciales en los materiales.

\section{Agradecimientos}

Se extienden agradecimientos al Dr. Yuriy Kudriastev y a la MC. Georgina Ramírez CINVESTAV México del Departamento de Ingeniería Eléctrica-SEES en MFA, así como a la MC. Lourdes Santiago Bautista y a la Ing. Diana Carolina Romo Mendoza de COMIMSA, a todos ellos por su importante colaboración en etapas preparación y caracterización del material de estudio.

\section{Referencias}

[1] Stainless Steel World. The last frontier: the hunt for deep sea oil and gas [página web]. 2014 [acceso el 15 de marzo 2014]. Disponible: http://www.stainless-steel-world.net/pdf/ssw_0806_offshore_Ir.pdf

[2] Mc Guire MF. Stainless steels for design engineers. New York: ASM International; 2008.

[3] Grocki, J. A primer for duplex stainles steel. Portland: Arcelor Mittal; 2012.
[4] Outokumpu Corporation. Outokumpu. 2013. [acceso el 6 enero 2014]. Disponible: http://www.outokumpu.com/en/Pages/ default.aspx

[5] Campbell RD. Professional's advisor on welding of stainless steel. Miami: American Welding Society; 1999.

[6] Lippold JC, Kotecki DJ. Welding metallurgy and weldability of stainless steels. Hoboken: John Wiley \& Sons; 2005. 
[7] Gunn R. Stainless steels. microstructure, properties and applications. Cambridge: Abington Publishing; 2003.

[8] García-García AL, Domínguez-López I, López-Jiménez L, Barceinas-Sánchez JDO. Comparative quantificaction and statistical analysis of $n^{\prime}$ and $n$ precipitates in aluminium alloy AA7075-T651 by TEM and AFM. Cerro Blanco: Elsevier; 2013. (vol. 87).

[9] Ureña A, Otero E, Utrilla MV, Múnez CJ. Weldability of a 2205 duplex satinless steels using plasma arc welding. Journal of Materials Processing Technology. 2007;182(1-3):624-631. http://dx.doi.org/10.1016/j.jmatprotec.2006.08.030.

[10] Yousefieh M, Shamaninan M, Saatchi A. Influence of heat input in pulsed current gtaw process on microstructure and corrosion resistance of duplex stainless steel welds. Iran: ScienceDirect, 2011. (vol. 18).

[11] Luo J, Dong Y, Li L, Wang X. Microstructure of 2205 duplex stainless steel joint in submerged arc welding by post weld heat treatment. Chongin: Elsevier; 2013.

[12] Mourad A-HI, Khourshid A, Sharef T. Gas tungsten arc and laser beam welding processes effects on duplex stainless steel 2205 properties. Emiratos Árabes Unidos: Elsevier; 2012.

[13] Badaji R, Bourabdallah M, Bacroix B, Kahloun C, Belkessa B, Maza $\mathrm{H}$. Phase transformation and mechanical behavior in annealed 2205 duplex stainless steel welds. Paris: Elsevier; 2007.

[14] Stephenson N. Welding status of duplex stainles steels for offsohre applications. United Kingdom: Nickel Development Institute; 1987.

[15] Sieurin H, Sandstörm R. Sigma phase precipitation in duplex stainless steel 2205. Estocolmo: Elsevier; 2006. p. 271-276. (vol. 444)

[16] Michalska J, Sozanska M. Qualitative and quantitatve analysis of sigma and chi phases in 2205 duplex stainles steel. Katowice: Elsevier; 2006. p. 355-362.

[17] Villalobos DI. Precipitación de fase sigma bajo la aplicación de ciclos térmicos en un acero inoxidable superdúplex SAF 2507. Morelia: Universidad Michoacana de San Nicolás de Hidalgo; 2011.

[18] Krauss G. Steels processing, structure and performance. New York: ASM International; 2005.

[19] Escriba DM, Materna-Morris E, Plaut RL, Padilha AF. Chi-phase precipitation in duplex stainless steel. Sao Paulo: Elsevier; 2009.

[20] Johnson D, Hilal N, Bowen WR. Basic principles of atomic force microscopy. In: Hilal N, Bowen WR. Atomic force microscopy in process engineering. Great Britain: Elsevier; 2009. p. 2-23.

[21] Liu L, XI N, Li G, Chen H. Atomic force microscope-based nanorobotic system for nanoassembly. In: Lai KWC, Xi N. Nanooptoelectronic sensors and devices: nanophotonics from design to manufacturing. Great Britain: Elsevier; 2012. p. 51-53.
[22] Ulyanov PG, Usachov DY, Fedorov AV, Bondareko AS, Senkovinski BV, Vivenko OF, et al. Microscopy of carbon steels: combained afm and ebs study. San Petersburgo: Elsevier; 2013.

[23] Instruments D. Magnetic Force Microscopy (MFM): applicable to dimension TM series and multimode TM systems. Santa Bárbara: Digital Instruments; 1996.

[24] Ferri FA, Pereira-da Silva MA, Marega E Jr. Magnetic force microscopy: basic principles and applications. São Carlos: Insituto de Física de São Carlos; 2012.

[25] Robbins R. Magnetc force microscopy operating procedure. Texas: University of Texas at Dallas; 2009.

[26] Liu H, Jin X. Secondry austenite morphologies in fusion zone of welded join after post weld heat treatment with a continuous wave laser. Shangai: Elsevier; 2012.

[27] Bettini E, Kivisakk U, Leygraf C, Pan J. Study of corrosion behavior of 2507 superduplex stainless steel: influence of quenched in and isothermal nitrides. International Journal of Electrochemical Science. 2014

[28] Bramfitt BL, Benscoter AO. Metallographer's guide: practices and procedures for irons and steels. New York: ASM International; 2002.

[29] Horcas I, Fernández R, Gómez-Rodríguez M, Colchero J, Gómez-Herrero J, Baro AM. WSXM: a software for scanning probe microscopy and tool for nanaotechnology. Review of Scientific Instruments. 2007;78:013705. http://dx.doi. org/10.1063/1.2432410.

[30] Dobrotvorskii AM, Masilkova EI , Shevyakova EP, Ul'ýanov PG, Usachev DYu, Senkovinsy BV, et al. Metallographic study of construction materials with atomic force microscopy method. Inorganic Materials. 2014. 50(15):1487-1494. http://dx.doi. org/10.1134/S0020168514150023.

[31] American Society for Testing and Materials. ASTM E1382-97: standard test methods for determining average grain size using semiautomatic and automatic image analysis. West Conshohoken: ASTM; 2004.

[32] Bhattacharjee PP, Zaid M, Sathiarj GD, Bhadak B. Evolution of microstructure and texture during warm rolling of duplex steel. Metallurgical and Materials Transactions A. 2014;45A:21802191.

[33] Pauletti E, Haskel HL, Martins JP, Carvalho LMC. Influence of delamination on microtexture and j-rcurve in API X60 steel. In: Proceedings of the 13th International Conference on Fracture; 2013 June 16-21; Beijing, China. Beijing: The Chinese Society of Theoretical and Applied Mechanics. p. 1-9.

[34] Shamanian M, Mohammadnezhad M, Amini M, Zabolian A Szpunar JA. Electron backscatter diffraction analysis of joints between aisi 316l austenitic/uns s32750 dual-phase stainless steel. Journal of Materials Engineering and Performance. 2015;24(8):3118-3128.http://dx.doi.org/10.1007/s11665-015$1597-8$ 